\title{
ENHANCED OIL RECOVERY USING LOCAL ALKALINE
}

\author{
P. Akpoturi ${ }^{1, *}$ and S. F. Ofesi ${ }^{2}$ \\ 1,2 Dept of Petroleum Engineering, Fed. University of Petroleum Resources, EfFurun, Delta State. NiGERIA \\ E-mail addresses: ${ }^{1}$ petersakpoturi1212@gmail.com, ${ }^{2}$ samofesi@yahoo.com
}

\begin{abstract}
Improvement in productivity is one of the Oil and Gas industry's biggest challenges. About $60 \%$ of crude Oil still lay trapped in the reservoir even after primary and secondary recovery process have been completed, hence the need for a method that further improves recovery. In this study, flooding experiment was conducted at laboratory condition to investigate the use of locally sourced alkaline in improving recovery on sand samples. The efficiency of the local alkaline (palm bunch ash) was compared with other conventional alkaline ( $\mathrm{NaOH}, \mathrm{KOH}$, and $\mathrm{Na}_{2} \mathrm{CO}_{3}$ ). Eight cores ( $\mathrm{A1}-\mathrm{A} \$$ and $\mathrm{C1}$ - C4) were prepared, saturated with formation brine of 30, 000ppm salinity; crude (light and medium) were then flowed through sand samples. The samples were individually flooded with brine for secondary recovery process where an average of 55\% of initial Oil in place was recovered. Each sample was flooded with different alkaline (local and conventional) for the tertiary recovery stage. The result obtained during flooding on samples saturated with light crude showed that $\mathrm{KOH}$ recovered $74 \%, \mathrm{NaOH}$ recovered $66 \%$, and palm bunch ash recovered an average of $64 \%$ while $\mathrm{Na}_{2} \mathrm{CO}_{3}$ recovered 59\%. It is recommended that the further studies to investigate the impact of the palm bunch ash should be carried out using heavy crude under reservoir conditions. These studies if successful will help and increase the use of local content which is relatively cheaper and this will in turn increase the local content drive of the Nigerian government in the oil and gas industry.
\end{abstract}

KEYWORDS: Secondary reservoirs, Flooding, Alkaline, Saturated, Samples, Brine, Local content, Enhanced recovery, Trapped.

\section{INTRODUCTION:}

The need for Enhanced Oil Recovery (EOR) production have increased over the years because of the decline in the discovery of new oil producing fields and the ever increasing demand for hydrocarbons[5]. There are also concerns that most of the newly discovered hydrocarbon fields do not contain oil that can easily be produced by natural reservoir pressure depletion drive, hence there is the need therefore to look for more efficient ways of extracting extra oil from existing brown and newly discovered green fields[19]. The oil industry is continuously researching, to find new, efficient and economical ways of recovering every drop possible from the mature or existing oil fields. In line with this, crude oil development and production has developed through three distinct phases: Primary, Secondary and Tertiary or Enhanced Oil Recovery.

Primary recovery is the initial production stage resulting from the displacement energy existing naturally in the reservoir. The natural energy sources are solution gas drive, gas - cap drive natural water drive, fluid and rock expansion and gravity drainage [1]. The recovery factor for this period is usually relatively low, around $5-30 \%$ on average of the original oil in place [7].

Secondary recovery is usually set in place immediately the primary recovery starts to decline. Since the natural energy of the reservoir has been depleted, and the reservoir cannot produce at an economic rate, energy (secondary), needs to be supplied from the surface. To increase production, the pressure in the reservoir can be maintained by injection of other fluids [3]. Traditional secondary recovery processes involves the injection of fluids which already exists in the reservoir, as water and gas. These fluids are injected to ensure pressure support by physical energy and the displacement of oil towards the production wells [15]. The most applied secondary recovery process is water flooding. The recovery factor for a reservoir that has undergone primary production followed by water flooding is between 35 to $50 \%$ of the original oil in place [2].

The target of tertiary recovery is the residual oil left behind after the secondary recovery process has become uneconomical. An EOR process may involve injection of miscible gases, chemicals and thermal energy into the reservoir to displace additional oil. Three main classes of 
enhanced oil recovery currently being applied in the oil and gas industry are thermal, gas and chemical methods [8-9].

Thermal methods, such as injecting steams recover the oil by introducing heat into the reservoir. This mechanism is the reduction of crude viscosity with increasing temperature. Thermal recovery continues to be an attractive means of maximizing the value and reserves from heavy oil assets [10]; [16]. However, thermal recovery methods are not so advantageous for light crude reservoirs because of the viscosity of the crude. In the gas method, particularly carbon dioxide $\left(\mathrm{CO}_{2}\right)$, recovers oil mainly by making the oil light when injected into the reservoir. Gas method sometimes are called solvent methods or miscible process [13]. Currently, gas methods account for most EOR production and are very successful especially for reservoirs with low permeability, high pressure and lighter oil [6]; [1]. However, gas methods are unattractive if the reservoir has low pressure or if it is difficult to find gas supply.

Chemical methods comprises of the use of polymers, surfactant flooding, foam flooding, alkaline flooding. The mechanisms of chemical methods vary, depending on the chemical materials added into the reservoir. The chemical methods may provide one or several effect of interfacial tension (IFT) reduction, Wettability alteration, emulsification and mobility control. Delshad et al [4] stated that the technical limitation of chemical flooding were insufficient understanding of the mechanisms involved and lack of scale up and is considered among the most promising chemical method in recent years, because it is possible to achieve interfacial tension reduction and wettabilityalteration.

Polymer flooding involves the addition of large molecular weight molecules called polymer to an injected water to increase the effectiveness of water flooding [14].They are added to the water in concentration ranging from 250 $2000 \mathrm{ppm}$. In flooding application, the viscosity alters the mobility ratio between the injected fluid and the reservoir fluid. The improved mobility ratio leads to better vertical and areal sweep efficiency and thus higher oil recovery [17].

Surfactant flooding involves using surfactants to lower the interfacial tension between the injected fluid and the reservoir oil. The surfactants migrate to the interface between the oil and water phase and help make the two phases more miscible. Common surfactants are soap and detergent. As the interfacial tension between oil and the water phase is reduced, the capacity of the aqueous phase to displace the trapped oil from the pores of the rock matrix increases.

Alkaline flooding in which an alkaline chemical such as sodium hydroxide, sodium orthosilicate or sodium carbonate alkaline chemical reacts with certain types of oil and forms surfactants inside the reservoir. Eventually, the surfactants play a big role to increase oil recovery by reducing interfacial tension between oil and water. The alkaline agents leads to the displacement of crude oil by raising the $\mathrm{pH}$ of the flooding water. The reaction between alkaline and acidic components in crude oil forms in situ surfactant at the oil - brine interface. Then the crude oil is mobilized by the mixture and the mixture removes oil from the pore spaces in the reservoir, the oil can then be moved easily through the reservoir to production wells [18].

Alkaline flooding is not recommended for carbonate reservoirs because of the profusion of calcium and the mixture between the alkaline chemical and the calcium ions can produce hydroxide precipitation that may damage the formation.

Alkaline flooding is a complex process where interfacial tension reduction is not always the key mechanism. Depending on the rock and crude properties, emulsification and wattability alteration can play a major role in oil recovery from mixed - wet naturally fractured carbonates [12-10-20].

\section{OBJECTIVE OF STUDY}

To study the forcibility of using locally sourced alkaline for EOR, considering the economic advantage and to compare the results with foreign alkaline.

Determination of displacement efficiency by alkaline solution injection using the conventional solution $(\mathrm{NaOH}$, $\mathrm{Na}_{2} \mathrm{CO}_{3}$ and $\mathrm{KOH}$ ) and the locally sourced alkaline (palm bunch ash)

\section{MATERIALS AND METHODS}

This study will involve the use of the following alkaline in performing core flooding experiments: Alkaline extract from palm bunch ash, sodium hydroxide, sodium carbonate and potassium hydroxide.

Reservoir crude oil (light and intermediate crude) from a Niger Delta field was used for the experiments. The oil was centrifuged for an hour and filtered through a $5.0 \mathrm{~mm}$ filter paper (with a vacuum pump) to remove any possible particles and water. (Table 1) below shows the properties of the crude oil.

Viscosity of the crude oil was obtained through the use of a canon glass viscometer with model number $614 \mathrm{~B}$ (150). The viscosity of the crude was measured at $22^{\circ} \mathrm{C}$. The brine used in the flooding experiment was sodium chloride ( $\mathrm{NaCl}$ ) based, with concentration of 30,000ppm. The brine were prepared by dissolving $30 \mathrm{~g}$ of sodium chloride in $30 \mathrm{ml}$ of distilled water and steamer (bar) until the salt was completely dissolved to obtain an efficient mix of solute and solvent. 


\begin{tabular}{cccc}
\multicolumn{4}{c}{ Table 1: Crude oil properties } \\
\hline $\begin{array}{c}\text { Type of crude } \\
\text { oil }\end{array}$ & $\begin{array}{c}\text { Density } \\
\text { (g/cc) }\end{array}$ & $\begin{array}{c}\text { Specific } \\
\text { gravity }\end{array}$ & $\begin{array}{c}\text { Viscosity } \\
\text { (cp) }\end{array}$ \\
\hline $\begin{array}{c}\text { Intermediate } \\
\text { crude }\end{array}$ & $\begin{array}{c}0.9114 @ \\
22^{\circ} \mathrm{C}\end{array}$ & 0.896 & $\begin{array}{c}33.2773 @ \\
22^{\circ} \mathrm{C}\end{array}$ \\
Light crude & $0.545 @$ & 0.841 & $\begin{array}{c}7.661 @ \\
22^{\circ} \mathrm{C}\end{array}$ \\
\hline
\end{tabular}

Table 2: Properties of brine used in the experiment

\begin{tabular}{cccc}
\hline $\begin{array}{c}\text { Salinity } \\
(\mathrm{ppm})\end{array}$ & $\begin{array}{c}\text { Density } \\
\mathrm{g} / \mathrm{cc}\end{array}$ & $\begin{array}{c}\text { Viscosity cp @ } \\
28^{\circ} \mathrm{c}\end{array}$ & $\begin{array}{c}P^{H} @ \\
37^{\circ} \mathrm{C}\end{array}$ \\
\hline 30,000 & 1.0453 & 1.000 & 7,60 \\
\hline
\end{tabular}

The porous medium (sand) used for the flooding experiment were unconsolidated, heterogeneous clay free sandstone cores. Eight sand samples were prepared. The pore volume of the cores was calculated from equation (1) the calculation is based on the weight different between dry and wet core $100 \%$ saturated with a brine of known density. The porosity was then determined from equation (2).

$$
P_{v}=\frac{W_{s}-W_{d}}{e_{s}}
$$

$\mathrm{Pv}$ is the pore volume of core (cc), $\mathrm{W}_{\mathrm{s}}$ is the Saturated weight of core $(\mathrm{g}), \mathrm{W}_{\mathrm{d}}$ is the Dry weight of core $(\mathrm{g})$ and $e_{s}$ is the Density of the saturate $(\mathrm{g} / \mathrm{cc})$

$$
\varnothing=\frac{p v}{V_{b}} \times 100
$$

In (2), $\phi$, is the porosity (\%); $\mathrm{Pv}$ is the pore volume of core (cc), $\mathrm{V}_{\mathrm{b}}$ is the bulk volume of core (cc)

The sand samples where $100 \%$ saturated with brine by leaving them in the brine for 48 hours. The cores were individually loaded into the rubber sleeve and then into the glass core holder. Light and medium crude oil was then flowed through the cores at a constant flow rate of 1 cc / sec, the pressure drops across the cores were recorded and the volume of effluent produced were collected in graduated tubes and their values recorded. The core samples (A1 - A4) were saturated with light crude while core samples (C1 - C4) were saturates with the medium crude oil. The volume of effluent recovered is taken as the initial oil in place.

Calculation of the irreducible water saturation (swi) from equation (3) by noting the difference between the pore volume and the volume of effluent (oil initially in place) recovered.

$$
S_{w i}=\frac{p v-N}{p v} \times 100
$$

$\mathrm{S}_{\mathrm{wi}}$ is the Irreducible water saturation (\%), $\mathrm{Pv}$ is the Pore volume (cc) and $\mathrm{N}$ is the Oil initially in place (cc)

The initial oil saturation for the cores was calculated using equation (4) or (5) noting the assumption that only two phases of fluid (oil and water) exist in the cores.

$$
S_{0 i}=1-S_{w i}
$$

$$
S_{0 i}=\frac{N}{p v} \times 100
$$

Residual oil saturation of the cores were calculated and recorded by the use of equation (6).

$$
S_{0 i}=\frac{N-N_{p}}{p v} \times 100
$$

Here, $\mathrm{S}_{\text {or }}$ is the Residual oil saturation (\%), $\mathrm{N}$ is the Oil originally in place (cc), $\mathrm{N}_{\mathrm{p}}$ is the Oil produced (cc) and Pv is thee Pore volume (cc)

\subsection{Procedure for Obtaining the Local Alkaline}

The alkaline used for this study was obtained from palm bunch; the procedure used in obtaining the local alkaline from the palm bunch is outlined as follows:

- Obtain a palm fruit bunch

- Cut and extract the palm fruit and separate it from the palm bunch

- Allow the palm bunch to dry so as to remove the inherent water.

- Burn the palm bunch and allow for complete combustion.

- Collect the palm bunch residue and dissolve same in water.

- Filter out the debris and dirt from the solution obtained.

- The obtained solution is our local alkaline.

\section{RESULTS AND DISCUSSIONS}

These experiments are designed to study the effect of alkaline agents on enhanced oil recovery. Results of the locally sourced alkaline were compared with the results of conventional (foreign) alkaline. The results obtained from the laboratory experiments using local and foreign alkaline as the flooding agents.

\subsection{Fluid Data}

Table 3 shows the properties of the formation brine, the crude and alkalis used in this experimental study. Four different alkalis tamely palm bunch ash (local alkali), sodium carbonate $\left(\mathrm{Na}_{2} \mathrm{CO}_{3}\right)$, potassium hydroxide $(\mathrm{KOH})$, and sodium hydroxide $(\mathrm{NaOH})$ were used. The density of the alkalis ranged from $0.8 \mathrm{~g} / \mathrm{cm}^{3}$ to $1.0 \mathrm{~g} / \mathrm{cm}^{3}$ which the viscosity range from $0.81 \mathrm{cp}$ to $1.107 \mathrm{cp}$, the palm bunch ash has an API gravity of 24.71 .

\subsection{Fluid Saturation Data}

Fluid saturation (gas, oil and water) value gives an idea of the fraction or percent of the pore volume a particular fluid can occupy in a reservoir. In this case, the fluid saturation is restricted to just oil and water because gas saturation is assumed to be zero. (Table 8) and figure (1) show the fluid saturation of the samples as a result of the injection and production of fluids into and from the samples.

Vol. 36, No. 2, April 2017 
Table 3: Fluid Properties

\begin{tabular}{llll}
\hline Fluid & Viscosity $(\mathrm{cp})$ & Density $\left(\mathrm{g} / \mathrm{cm}^{3}\right)$ & API gravity \\
\hline Brine & 1.0453 & 1.025 & 35.64 \\
Crude oil (intermediate) & 33.2773 & 0.9114 & 26.4 \\
Crude oil (light) & 7.611 & 0.545 & 36.8 \\
$\mathrm{Na}_{2} \mathrm{CO}_{3}$ & 1.0167 & 1.019 & 17.62 \\
$\mathrm{NaOH}$ & 1.107 & 1.0337 & 24.378 \\
$\mathrm{KOH}$ & 0.812 & 1.0228 & 23.16 \\
Local alkali (PBN) & 0.944 & 1.0016 & 24.71 \\
\hline
\end{tabular}

Table 4: Bulk volume of samples

\begin{tabular}{cccccccc}
\hline Sample & $\begin{array}{c}\text { Sample } \\
\text { pack } \\
\text { wt(g) }\end{array}$ & $\begin{array}{c}\text { Diameter of } \\
\text { sample } \\
\text { pack }(\mathrm{cm})\end{array}$ & $\begin{array}{c}\text { Length of } \\
\text { sample } \\
\text { pack (cm) }\end{array}$ & $\begin{array}{c}\text { Weight of } \\
\text { dry sand } \\
\text { +pack }(\mathrm{g})\end{array}$ & $\begin{array}{c}\text { Weight of sat } \\
\text { urated sand } \\
\text { + pack (g) }\end{array}$ & $\begin{array}{c}\text { Mass } \\
\text { difference (g) }\end{array}$ & $\begin{array}{c}\text { Bulk } \\
\text { volume } \\
\text { (cc) }\end{array}$ \\
\hline A1 & 19.773 & 3.3 & 6.2 & 108.389 & 128.483 & 20.094 & 53.0499 \\
A2 & 20.443 & 3.3 & 6.3 & 108.85 & 129.078 & 20.228 & 53.9055 \\
A3 & 19.994 & 3.3 & 6.2 & 108.796 & 128.795 & 19.999 & 53.0499 \\
A4 & 20.376 & 3.3 & 6.3 & 109.037 & 129.193 & 20.196 & 53.9055 \\
C1 & 20.228 & 3.3 & 6.2 & 109.03 & 129.195 & 20.165 & 53.0499 \\
C2 & 20.459 & 3.3 & 6.2 & 109.261 & 129.58 & 20.319 & 53.0499 \\
C3 & 20.398 & 3.3 & 6.2 & 109.2 & 128.482 & 19.282 & 53.0499 \\
C4 & 20.021 & 3.3 & 6.2 & 108.823 & 128.586 & 19.763 & 53.0499 \\
\hline
\end{tabular}

Table 5: Pore volume of the samples

\begin{tabular}{cccccccc}
\hline Sample & $\begin{array}{c}\text { Sample } \\
\text { pack } \\
\text { wt(g) }\end{array}$ & $\begin{array}{c}\text { Diameter of } \\
\text { sample } \\
\text { pack (cm) }\end{array}$ & $\begin{array}{c}\text { Length of } \\
\text { sample } \\
\text { pack (cm) }\end{array}$ & $\begin{array}{c}\text { Weight of } \\
\text { dry sand } \\
\text { + pack }(\mathrm{g})\end{array}$ & $\begin{array}{c}\text { Weight of } \\
\text { saturated sand } \\
\text { + pack }(\mathrm{g})\end{array}$ & $\begin{array}{c}\text { Mass } \\
\text { difference (g) }\end{array}$ & $\begin{array}{c}\text { Bulk } \\
\text { volume } \\
\text { (cc) }\end{array}$ \\
\hline A1 & 19.773 & 3.3 & 6.2 & 108.389 & 128.483 & 20.094 & 53.0499 \\
A2 & 20.443 & 3.3 & 6.3 & 108.85 & 129.078 & 20.228 & 53.9055 \\
A3 & 19.994 & 3.3 & 6.2 & 108.796 & 128.795 & 19.999 & 53.0499 \\
A4 & 20.376 & 3.3 & 6.3 & 109.037 & 129.193 & 20.196 & 53.9055 \\
C1 & 20.228 & 3.3 & 6.2 & 109.03 & 129.195 & 20.165 & 53.0499 \\
C2 & 20.459 & 3.3 & 6.2 & 109.261 & 129.58 & 20.319 & 53.0499 \\
C3 & 20.398 & 3.3 & 6.2 & 109.2 & 128.482 & 19.282 & 53.0499 \\
C4 & 20.021 & 3.3 & 6.2 & 108.823 & 128.586 & 19.763 & 53.0499 \\
\hline
\end{tabular}

Table 6: Porosity of core sample

\begin{tabular}{cccc}
\hline Sample & Bulk volume (cc) & Pore volume (cc) & Porosity (\%) \\
A1 & 53.0499 & 19.2236 & 36.2368 \\
\hline A2 & 53.9055 & 19.3518 & 35.8994 \\
A3 & 53.0499 & 19.1327 & 36.0655 \\
A4 & 53.9055 & 19.2829 & 35.7716 \\
C1 & 53.0499 & 19.2915 & 36.3648 \\
C2 & 53.0499 & 19.4388 & 36.6425 \\
C3 & 53.0499 & 18.4467 & 34.7724 \\
C4 & 53.0499 & 18.9069 & 35.6399 \\
\hline
\end{tabular}

Table 7: Showing fluid saturations data for brine flooding

\begin{tabular}{ccccc}
\hline Core & Pore volume $(\mathrm{cc})$ & $\mathrm{S}_{\mathrm{wi}}(\%)$ & $\mathrm{S}_{\mathrm{oi}}(\%)$ & $\mathrm{S}_{\text {or }}(\%)$ after water flooding \\
\hline A1 & 19.2236 & 29.77366 & 70.22634 & 33.81268 \\
A2 & 19.3518 & 30.23888 & 69.76112 & 31.00494 \\
A3 & 19.1327 & 29.44007 & 70.55993 & 33.9733 \\
A4 & 19.2829 & 29.98968 & 70.01032 & 38.89462 \\
C1 & 19.2915 & 45.57183 & 54.42817 & 23.32636 \\
C2 & 19.4388 & 45.98435 & 54.01565 & 20.57739 \\
C3 & 18.4467 & 43.07935 & 56.92065 & 24.39456 \\
C4 & 18.9069 & 44.46471 & 55.53529 & 21.1563 \\
\hline
\end{tabular}


Table 8: Showing Fluid Saturations Data for Brine Flooding

\begin{tabular}{ccccc}
\hline Core & Pore volume $(\mathrm{cc})$ & $\mathrm{S}_{\mathrm{wi}}(\%)$ & $\mathrm{S}_{\mathrm{oi}}(\%)$ & $\mathrm{S}_{\text {or }}(\%)$ after water flooding \\
\hline A1 & 19.2236 & 29.77366 & 70.22634 & 33.81268 \\
A2 & 19.3518 & 30.23888 & 69.76112 & 31.00494 \\
A3 & 19.1327 & 29.44007 & 70.55993 & 33.9733 \\
A4 & 19.2829 & 29.98968 & 70.01032 & 38.89462 \\
C1 & 19.2915 & 45.57183 & 54.42817 & 23.32636 \\
C2 & 19.4388 & 45.98435 & 54.01565 & 24.57739 \\
C3 & 18.4467 & 43.07935 & 56.92065 & 21.1563 \\
C4 & 18.9069 & 44.46471 & 55.53529 & \\
\hline
\end{tabular}

\subsection{Water Saturation}

It can be inferred from the results in (Table 8) that the initial water saturation $\left(\mathrm{S}_{\mathrm{wi}}\right)$ of the cores was between $29 \%$ and $45 \%$ of the pore volume. The water saturation value peaked at about $46 \%$. The importance of the irreducible water saturation is that it gives an idea of the available pore space that can be occupied by another fluid, in this case oil, because the sum total of the individual fluid saturation in equal to unity.

\subsection{Initial Oil Saturation}

The initial oil saturation presented in (Table 8) is as calculated. It is the fraction of the pore volume that is occupied by oil. Though not all the oil contained in the pore spaces of the sample will be recovered due to critical saturation and capillary forces that holds the oil within the pore spaces of core, the initial oil saturation gives a practical measure of the oil available for production.

\subsection{Residual Oil Saturation}

The residual oil saturation of the core samples presented in (Table 8) was calculated using Equation 3. It is a measure of the oil left (residual) in the samples after the process of water flooding. It gives an idea of the water flooding process. Based on the result presented, the water flooding process may be regarded as efficient, since it is a secondary recovery process, meaning some amount of oil can still be recovered by tertiary recovery processes.

Table 9 show the saturation data for the cores during the alkaline flooding carried out of tertiary recovery. It can be inferred from Table 9 that after the recovery of oil by water flooding, the irreducible water saturation of the cores increased, thereby causing a simultaneous decease of the initial oil saturations of the cores. Also the residual saturation of the cores was also reduced after the alkaline flooding.

\subsection{Flooding Process for Secondary and Tertiary Stage Recoveries}

This section presents and discusses the results obtained from the recovery process (secondary and tertiary stage) of this experimental research work. The flooding process was conducted using brine, prepared alkalis, (local and conventional) to recover light crude and intermediate crude oil samples from the cores at secondary and tertiary stage respectively. The recovery in different crude samples is as shown in Table 9.

Table 9: Showing Result of the Recoveries of the Samples

\begin{tabular}{|c|c|c|c|c|c|c|c|c|}
\hline $\begin{array}{l}\text { Samp } \\
\text { les }\end{array}$ & $\begin{array}{l}\text { Alkaline EOR } \\
\text { agents }\end{array}$ & $\begin{array}{l}\text { Volume } \\
\text { of crude } \\
\text { oil } \\
\text { injected } \\
(\mathrm{ml})\end{array}$ & $\begin{array}{l}\text { Recovery } \\
\text { factor (\%) } \\
\text { by brine }\end{array}$ & $\begin{array}{c}\text { Tertiary } \\
\text { recovery } \\
\text { by } \\
\text { alkaline } \\
(\%)\end{array}$ & $\begin{array}{l}\text { Total oil } \\
\text { recovery } \\
(\%)\end{array}$ & $\begin{array}{c}\text { Displacement } \\
\text { efficiency }\end{array}$ & $\begin{array}{l}P^{H} \text { values } \\
\text { of the } \\
\text { alkaline }\end{array}$ & Remarks \\
\hline \multicolumn{9}{|c|}{ INTERMEDIATE CRUDE } \\
\hline A1 & $\mathrm{Na}_{2} \mathrm{CO}_{3}$ & 13.50 & 51.85 & 7.41 & 59.26 & 15.38 & 10.10 & Lowest \\
\hline A2 & $\mathrm{NaOH}$ & 13.50 & 51.85 & 14.81 & 66.66 & 30.77 & 12.10 & High \\
\hline A3 & $\mathrm{KOH}$ & 13.50 & 55.56 & 18.52 & 74.08 & 41.67 & 13.20 & Highest \\
\hline A4 & Palm bunch ash & 13.50 & 52.56 & 11.11 & 63.67 & 21.54 & 11.50 & Good \\
\hline \multicolumn{9}{|c|}{ LIGHT CRUDE } \\
\hline $\mathrm{C} 1$ & $\mathrm{Na}_{2} \mathrm{CO}_{3}$ & 10.50 & 57.14 & 11.91 & 69.5 & 27.78 & 10.10 & Lowest \\
\hline $\mathrm{C} 2$ & $\mathrm{NaOH}$ & 10.50 & 59.90 & 23.81 & 83.71 & 62.50 & 12.10 & High \\
\hline $\mathrm{C} 3$ & $\mathrm{KOH}$ & 10.50 & 57.14 & 28.57 & 8571 & 66.67 & 13.20 & Highest \\
\hline $\mathrm{C} 4$ & Palm bunch ash & 10.50 & 58.14 & 19.05 & 77.19 & 50.00 & 11.50 & Good \\
\hline
\end{tabular}




\subsection{Recovery of Intermediate Crude through Water flooding}

Cores A1 - A4 containing intermediate (medium) crude was flooded with recovery brines of 30,000 ppm salinity concentration. The water flooding was carried out as a secondary stage recovery process. The results obtained during the water flooding process to recover the intermediate crude shows that recovery was between $6 \mathrm{cc}$ (44.44\% of oil in place) and $7.5 \mathrm{cc}$ (55.56\% of oil in place). Table 9 shows a graphical representation of the volume and percentage of intermediate oil recovered from cores A1 - A4.

It can be inferred from Table 9 that of all the four cores used, the highest volume of oil (7.5cc, 55.56\%) was recovered from core $\mathrm{A} 3$, while the least recovery was from core A4 (6cc, 44.44\%).

\subsection{Recovery of Light Crude Oil by Water Flooding}

Samples C1 - C4 containing light crude was flooded with recovery brines of $30,000 \mathrm{ppm}$ salinity concentration. The water flooding was carried out as a secondary stage recovery process. The results obtained during the water flooding process to recover the light crude shows that the volume of the oil in place is $10.5 \mathrm{cc}$, oil recovery was between $6 \mathrm{cc}$ (57.14\% of oil in place) and $6.5 \mathrm{cc}(61.90 \%$ of oil in place). Table 9 shows the volume and percentage of oil recovered from cores C1 - C4. It can be inferred from Table 9that of the four cores used, the highest volume of oil $(6.5 \mathrm{cc}, 61.90 \%)$ was recovered from cores $\mathrm{C} 2$ and $\mathrm{C} 4$, while the least recovery (6cc, 57.14) was from cores $\mathrm{C} 1$ and $\mathrm{C} 3$.

\subsection{Tertiary Stage Recovery of Crude Oil by Alkaline Flooding}

This section deals with the main flooding experiment at the tertiary stage. The aim is to compare the effectiveness of locally sourced alkaline and conventional (foreign) alkaline as flooding agents. The alkaline were used to flood cores A1 - A4 (containing medium crude) and cores C1 - C4 (containing light crude) for tertiary state recovery process. Four different alkaline were used for the flooding process for both the intermediate and light crude oil samples. The alkaline are sodium hydroxide $(\mathrm{NaOH})$ sodium carbonate $\left(\mathrm{Na}_{2} \mathrm{CO}_{3}\right)$, potassium hydroxide $(\mathrm{KOH})$ and the locally sourced palm bunch ash (PBA). Highlights of the results obtained from these processes are presented as follows.

\subsection{Recovery of Intermediate Crude by Alkaline Flooding} Samples A1 - A4 containing intermediate crude was first flooded with brine at a secondary stage recovery. The volume of oil recovered was between $40 \%$ and $55 \%$, leaving behind an enormous $45 \%$ to $60 \%$ of residual oil. This is the justification for an economical recovery process to recover the residual oil in the cores, hence the tertiary recovery process of alkaline flooding. Table 9 shows the results obtained after the alkaline flooding processes to recover the residual intermediate crude after the water flooding process.

It can be observed from Table 9 that the alkaline recovery is between $1 \mathrm{cc}$ (15.35\% of oil in place) and $2.5 \mathrm{cc}(41.67 \%$ of oil in place). $\mathrm{KOH}$ gave the best recovery of $2.5 \mathrm{cc}(41.67 \%)$, while $\mathrm{Na}_{2} \mathrm{CO}_{3}$ gave the least recovery of $1 \mathrm{cc}(15.35 \%)$. The local alkaline (PBA), however gave a recovery of $1.5 \mathrm{cc}$ (20\%). Comparatively, $\mathrm{KOH}$ gave the best recovery of all the alkaline used.

\subsection{Recovery of Light Crude by Alkaline Flooding}

After the secondary stage recovery of light crude from cores $\mathrm{C} 1$ - $\mathrm{C} 4$, the volume of oil recovered ranged between $6 \mathrm{cc}(57 \%)$ and $6.5 \mathrm{cc}(62 \%)$, leaving behind a residual oil of between $4 \mathrm{cc}(43 \%)$ and $4.5 \mathrm{cc}$ (38\%). Though it can be adequately argued that in real life that if productions like this can be obtained at secondary stage recovery, we can as well forget about tertiary stage recovery process because it might prove uneconomical. However, for the purpose of this study the tertiary stage recovery through alkaline flooding will still be carried out.

Table 9 shows the alkaline flooding process. It can be inferred from Table 9 that the alkaline recovery is between $1 \mathrm{cc}(22.22 \%$ of oil in place) and 3cc (77.78\% of oil in place. $\mathrm{KOH}$ gave the best recovery of 3cc (77.78\%), while $\mathrm{Na}_{2} \mathrm{CO}_{3}$ gave the least recovery of $1 \mathrm{cc}(22.22 \%)$. The local alkaline (PBA) however gave a recovery of 2cc ( $50 \%$ of oil in place). Comparatively, $\mathrm{KOH}$ gave the best recovery of all the alkaline used.

\section{OBSERVATIONS AND FINDINGS}

High $P^{H}$ values give high displacement efficiency for both intermediate and light crude.

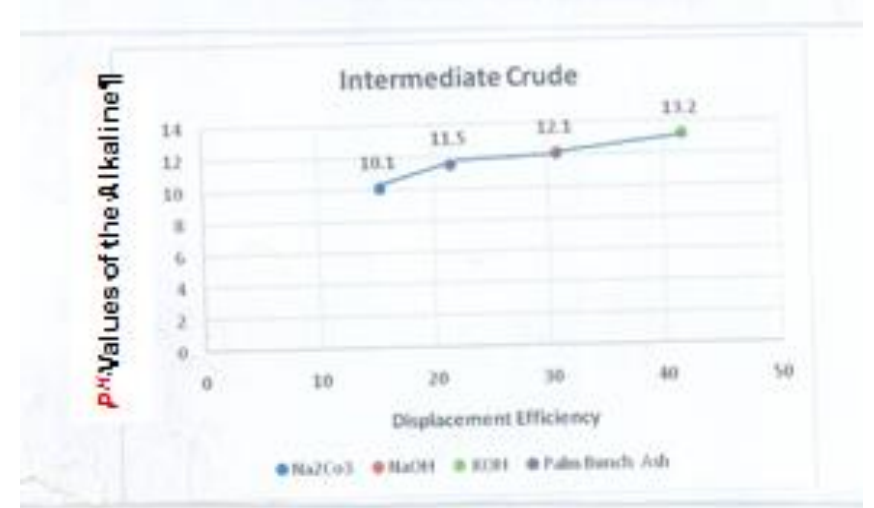

Figure 1: Displacement efficiency $/ P^{H}$ value for intermediate crude.

Vol. 36, No. 2, April 2017 


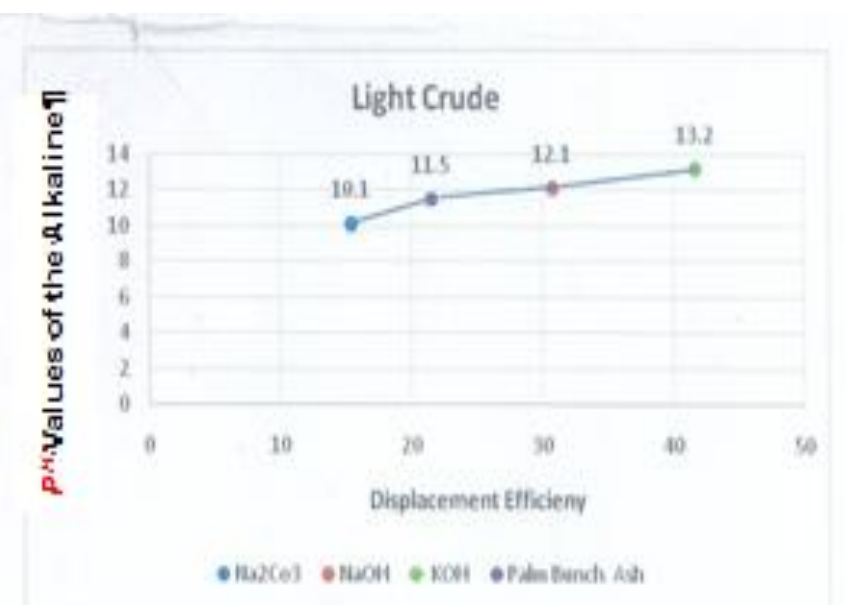

Figure 2: Displacement efficiency $/ P^{H}$ value for light crude

Oil recovery factor for light crude is generally higher than that of intermediate crude.

The displacement efficiency of the Palm bunch ash, was better than that $\mathrm{Na}_{2} \mathrm{CO}_{3}$ only amongst the four alkaline agents tested but its performance is low compared to $\mathrm{KOH}$ and $\mathrm{NaOH}$.

Recovery of crude using $\mathrm{KOH}$ alkaline is the best amongst the four alkaline agents tested.

\section{CONCLUSION}

The use of alkali as a flooding agent in tertiary recovery scheme has been demonstrated in this experimental study. Based on this study, the following conclusions are made: The flooding alkali $\left(\mathrm{Na}_{2} \mathrm{CO}_{3}\right),(\mathrm{NaOH})$, and $(\mathrm{KOH})$ and the local alkali (PBA) showed significant residual oil comparatively. However $\mathrm{KOH}$ gave the best residual oil recovery for both light and intermediate crude. Potassium hydroxide solution gave the best recovery when compared with the other alkali used in this experiment. The improved recovery can be attributed to in-situ saponification that occurs between the alkali solution and the contained in the crude oil. This leads to reduction in interfacial tension between the crude oil and formation.

Though the experiment was to ascertain the effect of locally sourced alkali, the result showed that the locally sourced alkali did not give the best recovery.

\section{REFERENCES}

[1]. Burk, J. H. "Comparison of Sodium Carbonate, Sodium Hydroxide, and Sodium Orthosilicate for EOR", Journal of Petroleum Technology Vol. 11, Number 9,.pp 20 - 23. 1987.

[2]. Chang, H. L. Zhang, Z. Q. Wang, Q. M. Xu, Z. S. Guo, Z. D. Sun, H. Q. Cao, X. L. and Qiao, Q. "Advances in Polymer Flooding and alkaline/ Surfactant/Polymer Processes as Developed and Applied in the people's
Republic of China" Journal of Petroleum Technology, Vol. 7, Number 8, pp84 - 89. 2006.

[3]. Cheng, K. H. "Chemical Consumption During Alkaline Flooding: A Comparative Evaluation" SPE 14944, presented at the 5th Symposium on Enhanced Oil Recovery of the Society Petroleum Engineers. April pp 64 - 69. 2006,

[4]. Delshad, M., Han. W., Pope, G. A., Sepehronoori, K., Wu, W., Yang, R., and Zhao, L. "Alkaline / Surfactant / Polymer Flood Predictions for the Karamay Oil Field", SPE 39610, SPE / DOE Improved Oil Recovery Symposium, 19 - 22 April Tulsa, Oklahoma. 1998.

[5]. Falls, A. H., " A Field Test of Co surfactant Enhanced Alkaline Flooding", SPE 24117, Presented at the SPE/DOE 8th Symposium on Enhanced Oil Recovery, Tulsa, Oklahoma, 1992.

[6]. Fan, T. and Buckley, J. S. "Acid Number Measurements Revisited", SPE 99884, Presented at the SPE/DOE Symposium on Improved Oil Recovery in Tulsa, Oklahoma, 22 - 26 April 2008.

[7]. Greaser, G. R., "New Thermal Recovery Technology and Technology Transfer for Successful Heavy Oil Development", SPE 69731, Presented at the 2010 SPE International Thermal Operations and Heavy Oil Symposium held in Porlamar, Margarita Island, Venezuela, 12 - 14 March 2010.

[8]. Healy, R. N., and Reed, R. L."Multiphase Micro emulsion Systems" Journal of Petroleum Technology, Vol. 3, Number 7, pp3 - 6. 2006.

[9]. Healy, R. N. and Reed, R. L. "Immiscible Micro emulsion Flooding", SPEJ, April, 129 - 139. 1977.

[10]. Hirasaki, G. J. “The steam - foam process", Journal of Petroleum Technology, Vol. 5, Number 3, 2011, pp 4 $-7$.

[11]. Krumrine, P. H., Flacone, J. S., and Campbell, T. C. "Surfactant Flooding I: The Effect of Alkaline Additives on IFT, Surfactant Adsorption, and Recovery Efficiency", SPEJ, Vol. 6, Number 6, pp 503 - 513. 1982

[12]. Li, H., Liao, G., Han, P., Yang, Z., Wu, X., D., and Jin, P. "Alkaline / Surfactant/Polymer (ASP) commercial Flooding Test in central Xing2 Area of Daqing Oil field", SPE 84896, presented at the SPE International Improved Oil Recovery Conference in Asia Pacific in Kuala Lumpur, Malaysia, $20-21$ October 2013

[13]. Miller, C. A., and Neogi, P. "Interfacial Phenomena” Surfactant Science Series, Vol. 17, Number 6, pp 20 $-23.1985$.

[14]. Morrow, N. R. "Wettability and its Effect on Oil Recovery", Journal of Petroleum Technology, Vol. 5, Number 7 1999, pp 1476 - 1484. 
[15]. Nelson, R. C. Lawson, J. B., Thigpen, D. R. and Stegemeier, G. L. "Co-surfactant Enhanced Alkaline Flooding”, SPE 12672, 1984.

[16]. Nguyen, Q. P., Alexandrov A. V., Zitha P. L., Currie P. K. "Experimental and Modeling Studies on Foam in Porous Media: A Review", SPE 58799, presented at SPE International Symposium on Formation Damage Control, Lafayette, Louisiana, February 2000.

[17]. Sanz. C. A. and Pope, G. A. "Alcohol-Free Chemical Flooding: From Surfactant Screening to Core flood Design", SPE 28956, Proceedings of the SPE International Symposium on Oil field Chemistry, San Antonio, TX, February 14 - 17, 2005.
[18]. Wardlaw, N. C. "Factors Affecting Oil Recovery from Carbonate Reservoirs and Prediction of Recovery", in Carbonate Reservoir Characterization: A Geologic Engineering Analysis, Part II, Chilingarian, G. V., Mazzullo, S. J., and Rieke, H. H., ed., Elsevier, New York, 867, 1996.

[19]. Wagner, O. R., and Leach, R. O. "Improving Oil Displacement Efficiency by wattability Adjustment", Petroleum Transactions, AIME, 216, 65 - 72, 1999.

[20]. Zhang, D. L., Liu, S., Yan, W., Puerto, M., Hirasaki, J., Miller, C. A. "Favorable Attributes of Alkali Surfactant - Polymer Flooding", SPE 99744, Presented at the SPE /DOE Symposium on Improved Oil Recovery in Tulsa, Oklahoma, 22 - 26 April 2006. 